\title{
NOTA SOBRE EL APORTE DE SOAJE RAMOS AL ENTENDIMIENTO DE LA NOCIÓN DE RATIO EN CAYETANO
}

\author{
CEFERINO P.D. MUÑOZ \\ CONICET-UMendoza-UNCuyo
}

\begin{abstract}
RESUMEN: Este trabajo pone en valor el estudio que Guido Soaje Ramos realizara del De nominum analogia de Cayetano, especialmente en torno al término ratio. En este sentido, el estudio del autor argentino se destaca por su rigor, erudición y por la originalidad con que supo esclarecer la forma mentis cayetaniana en un texto de gran dificultad como lo es el De nominum analogia. Asimismo, nuestro escrito - a partir del aporte de Soaje- muestra la evolución que la noción de ratio experimentó después de Tomás de Aquino hacia una vertiente de índole lógica, especialmente en su más reconocido comentador, Tomás de Vio Cayetano.
\end{abstract}

PALABRAS CLAVE: Guido Soaje Ramos, Cayetano, ratio, analogía, concepto.

\section{Note about the contribution of Soaje Ramos to the understanding of the notion of ratio in Cajetan}

ABSTRACT: This paper shows the value of Guido Soaje Ramo's research about De nominum analogia of Cajetan, especially relating to the term ratio. The study of this Argentine author is remarkable for its rigor, erudition, originality, and could clarify the Cajetan's forma mentis notion in a text of great difficulty as it is De nominum analogia. Also, our writing - about the contribution of Soaje- shows the evolution of the notion of ratio experienced after Thomas Aquinas to a logical sense, especially in its most recognized commentator, Thomas de Vio Cajetan.

KEY WORDS: Guido Soaje Ramos, Cajetan, ratio, analogy, concept.

\section{Breve semblanza de Soaje Ramos}

Guido Soaje Ramos nació en Córdoba el 4 de noviembre de 1918 y falleció en esa provincia, en la localidad de Alta Gracia, el 13 de marzo de $2005^{1}$. Cursó sus estudios universitarios en la Universidad Nacional de Córdoba, en donde obtuvo el título de abogado y más tarde el de doctor en Derecho y Ciencias Sociales. Su tesis doctoral versó sobre el concepto de ley en Suárez y su paralelo con el de Tomás de Aquino. En ella mostró la dependencia del Doctor Eximio con respecto a la doctrina de Juan Duns Escoto, en especial en cuanto a la noción de precepto, entendido como acto de imperio, y el consiguiente matiz voluntarista que resultaría de ello.

En la Facultad de Filosofía y Letras de esa casa de altos estudios enseño Ética, Historia de la Filosofía y Epistemología hasta 1958, año en que le impiden continuar en sus cátedras por cuestiones políticas. Poco después fue contratado por la Universidad de Río Grande do Sul (Brasil) para enseñar Ética. Al regresar a la Argentina retomó su actividad docente en diversos centros académicos en las cátedras de Introducción a

1 Seguimos el escrito de uno de los discípulos de Soaje, el Dr. MassinI Correas, C. I., «Perfil intelectual del Dr. Guido Soaje Ramos», Cuyo. Anuario de Filosofía Argentina y Americana 15 (1992), pp. 237-238. 
los problemas de la filosofía, Ética, Filosofía Social y Filosofía del Derecho. También fue investigador y Coordinador Científico en el área de Ciencias Humanas del Consejos Nacional de Investigaciones Científicas y Técnicas (CONICET). A inicios de los años setenta funda el Instituto de Filosofía Práctica, encargado de editar la revista Ethos, cuyo primer director fue el mismo Soaje.

En cuanto a sus temas de estudio, los mismos se orientaron principalmente en cuatro direcciones: la Filosofía Moral, la Filosofía Social, el concepto de Bien Común y la Filosofía del Derecho². Con todo, y a pesar de sus dotes intelectuales, su producción bibliográfica fue exigua ${ }^{3}$. Tal situación es explicada por Massini Correas:

«Su gran dominio de los idiomas clásicos y de los europeos, le ha dado acceso a una bibliografía de cantidad y calidad inusual en el país; quizá sea esta misma erudición, unida a un rigorismo poco común en el tratamiento de los problemas, la que haya impedido que G.S.R. publicara en la medida en que su enorme capacidad se lo permite» ${ }^{4}$.

Sin embargo, esto no obsta para que Soaje Ramos sea uno de los pensadores tomistas más serios, eruditos y profundos que haya dado Argentina. Y como observa Caturelli: «Sus escritos de gran rigor [...] producen en el ánimo del estudioso la impresión de que aún debemos esperar mucho más. La publicación de sus escritos y cursos inéditos corroborarán, seguramente, esa impresión» ${ }^{5}$.

\section{El aporte de Soaje Ramos}

Tal como ya dijimos, si bien Soaje se destacó principalmente - tanto en docencia como en investigación- en el ámbito de la filosofía práctica, tuvo contadas pero valiosísimas incursiones en metafísica. En el presente artículo haremos referencia a una de ellas, a saber, a la interpretación que realiza del significado de ratio en el más conocido de los representantes de la segunda escolástica: Tomás de Vio Cayetano. Soaje circunscribe el uso que el Cardenal hace de tal noción al De nominum analogia, pues es una de las obras que el autor argentino tuvo la posibilidad de estudiar en profundidad e incluso de traducir al castellano; la cual, dicho sea de paso, fue la primera traducción en esa lengua ${ }^{6}$. Sin embargo, cabe destacar que dicha traducción ha tenido escasísima difusión, al punto que es desconocida entre los mismo estudiosos de Cayetano. Es el caso del español Juan Antonio Hevia Echeverría, autor de la última traducción castellana del De nominum analogia ${ }^{7}$,

2 Cfr. Caturelli, A., Historia de la Filosofía en la Argentina. 1600-2000, Ciudad Argentina, Buenos Aires, 2001, p. 880. Caturelli toma esta división del ya citado escrito de Massini Correas.

3 No así en cuanto a sus escritos de crítica bibliográfica: «Además ha publicado muy numerosos trabajos de crítica bibliográfica, algunos de ellos muy extensos y con gran aparato crítico». Massini CoRreas, «Perfil intelectual...», p. 238.

4 Massini Correas, C. I., "Perfil intelectual...», pp. 241-242.

5 Cfr. Caturelli, Historia de la Filosofía..., p. 881.

6 Cfr. Cayetano, De nominum analogia. Texto latino según ed. Zammit O.P., (con notas de Zammit). Trad. y notas de Soaje Ramos, G., Universidad Nacional de Cuyo, Instituto de Filosofía, Mendoza, 1949. El análisis de Soaje Ramos del término ratio se extiende entre las pp. 253-258.

7 Hevia Echevarría, J. A., Tratado sobre la analogía de los nombres, Tratado sobre el concepto de ente, Biblioteca Filosofía en español, Oviedo, 2005. 
quien para su trabajo consultó las dos traducciones francesas ${ }^{8}$, las dos inglesas ${ }^{9} \mathrm{y}$, según él cree, la única española ${ }^{10}$, omitiendo — creemos que por desconocimientola de Soaje. Sin entrar en la discusión sobre la calidad de la traducción en sín ${ }^{11}$, el punto más valioso que nos interesa resaltar del aporte de Soaje radica en el metódico orden, pero sobre todo en la agudeza con que supo desentrañar el núcleo del pensamiento cayetaniano en torno a la noción de ratio.

Yendo a la obra en cuestión, Soaje señala en primer lugar la polisemia del término ratio en Santo Tomás, al cual califica de cuenca semántica ${ }^{12}$ por la riqueza y profundidad de significados que encierra ${ }^{13}$. Por ello, agrupa la noción en cuatro sentidos que toma directamente de la letra aquiniana ${ }^{14}$ : a- como cierta potencia cognoscitiva, b- como causa, c- como aquello que designa las cuentas (en el sentido de pedir cuentas) y d-como algo simple abstraído de una multiplicidad (como la esencia de hombre es abstraída de los singulares por la consideración de la mente $)^{15}$.

Luego de hacer algunas apreciaciones al respecto, explica que Cayetano usará

8 Pinchard, B., Métaphysique et sémantique, autour de Cajétan (Étude et traduction du De nominum analogia), Vrin, Paris, 1987 y RobILlard, H. M., De l'Analogie et du Concept d'Être de Thomas de Vio, Les Presses de l’Université de Montréal, Montréal, 1963.

9 Hochschild, J., The Semantics of Analogy: Rereading Cajetan's De Nominum Analogia, University of Notre Dame Press, Notre Dame, 2010 y Bushinski, E., y Koren, H., The Analogy of Names and the Concept of Being, Duquesne University Press, Pittsburgh, 1953.

10 Igual L., Vicente, La analogía (Estudio preliminar, traducción y notas al De nominum analogia), PPU, Barcelona 1989.

11 Hevia Echeverría es muy crítico de la versión de Vicente Igual Luis; al respecto dice que la misma "[...] se situaría en un término medio entre las dos anteriores [la de Hochschild y la de Pinchard], compartiendo sus defectos, aunque no sus virtudes; su traducción se asemeja a la de Hochschild en términos de literalidad, pero, a diferencia de éste, comete numerosos errores [...] así pues, Igual hace decir a Cayetano cosas que éste no dice y además nos priva de lo que dice [...]». Hevia Echevarría, Tratado sobre la analogía..., p. 38.

12 Una primera aproximación a la noción de ratio puede verse en Jolivet, R., Diccionario de Filosofía, Club de Lectores, Buenos Aires, 1989, pp. 152- 153. Más actual cfr. Magnavacca, S., Léxico técnico de Filosofía Medieval, Miño y Dávila, Buenos Aires, 2014, pp. 588-590. Si bien la autora se extiende más que Jolivet al explicar la noción, aun así dice que su análisis será restringido toda vez que «abordar todos los matices hubiera redundado en una extensión excesiva». MAGNAVACCA, Léxico técnico, p. 21. Para el sentido que tenía la noción en el siglo XIII y XIV cfr. DE RIJK, Lambertus Marie, "A special use of ratio in 13th and 14th century metaphysics", in M. Fattori - M.L. Bianchi, Ratio. VII Colloquio del Lessico Intellettuale Europeo, L.S. Olschki, Firenze 1994, pp. 197-218. Para un abordaje en la opera tomasiana cfr. BusA, R., "Vocis ratio, quae in Thomae Aq. propriis operibus 36.335 vicibus occurrit rationes atque numeros paucis hic conabar absolvere verbis», in M. Fattori - M.L. Bianchi, eds., Ratio. VII Colloquio Internazionale del Lessico intellettuale europeo, Leo S. Olschki, Firenze 1994, pp. 173-195.

13 Cayetano, De nominum analogia..., p. 253.

14 «Ex nomine autem rationis, quatuor intelliguntur: primo quidem dicitur esse quaedam cognoscitiva virtus; [...] Alio modo, ponitur pro causa, ut cum dicitur: qua ratione hoc fecisti? Idest, qua de causa? Et sic Deus dicitur ratio, non solum quia ipse est omnium causa, sed quia etiam omnes causas secundas in seipso causaliter praeaccipit, non tamen per modum compositionis, sed per modum uniformitatis et simplicitatis. Tertio modo, dicitur ratio etiam computatio, sicut habetur Matth. 18, quod rationem coepit ponere cum servis suis. [...] Quarto modo, dicitur ratio aliquid simplex abstractum a multis, sicut dicitur ratio hominis id quod per considerationem abstrahitur a singularibus, ad hominum naturam pertinens». Tomás DE Aouino, De divinis nominibus, cap. 7, lectio 5. Los resaltados nos pertenecen.

15 Cayetano, De nominum analogia..., p. 256. 
ratio primordialmente en el cuarto de los sentidos consignados, y éste es el que indagará Soaje. Sin embargo, advierte que previo al análisis será necesario tener en cuenta el contexto teórico en el cual se inserta la noción de marras. Esto es, en el conceptualismo realista heredado de Aristóteles y perfeccionado por el tomismo. Dicha doctrina contiene los siguientes postulados:

«1.- la relación entre cosas [sujeto transobjetivo] y objeto;

2.- la distinción entre los tres modos de existir de la «cosa»: entitativo, intencional y objetivo;

3.- la distinción entre concepto mental y concepto objetivo [u objeto de concepto]:

4.- la relación entre término [voz significativa] y concepto mental, concepto objetivo y cosa» ${ }^{16}$.

El profesor argentino sostiene que ratio pertenece originalmente al contexto lógico y que designa el objeto de concepto o "concepto objetivo», en tanto que conocido o existente en el espíritu. Por eso el estrecho parentesco semántico entre ratio, intentio ${ }^{17}$ y definitio ${ }^{18}$. Asimismo, para Soaje cuando se habla de ratio o bien se puede estar haciendo referencia al sujeto cognoscente o bien a la cosa extramental; y a veces de modo independiente a cada uno, pues ratio no siempre corresponde a una realidad extra anima. Ahora bien, cuando sí corresponde, ratio también puede indicar un vínculo al ser extramental, y en este caso la perspectiva sería propiamente metafísica.

Según Soaje, también puede tomarse ratio para indicar las ideas divinas que son llamadas rationes ideales. Asimismo, las rationes pueden remitir a los diversos puntos de vista desde los cuales el espíritu considera una misma cosa, y finalmente a los principios de especificación de las ciencias.

Pasando en limpio lo dicho: de acuerdo con nuestro autor, de los diez sentidos en que puede entenderse ratio, Cayetano, en el De nominum analogia, sólo la usa en seis, a saber:

1. Como concepto objetivo ${ }^{19} \mathrm{o}$ - lo que es lo mismo- la cosa en cuanto representada y entendida, i.e., en cuanto término del acto intelectual ${ }^{20}$;

16 Cayetano, De nominum analogia..., p. 255. Los resaltados y corchetes pertenecen al autor.

17 Para Soaje la expresión intentio remite al concepto del entendimiento, y se dice intentio porque tiende (tendit) al objeto. Asimismo, esta intentio puede ser formal u objetiva, es decir o remite al conocimiento mismo o bien a la cosa conocida. Distinción que al mismo tiempo señala la doble faz del concepto: formal y objetiva. En suma, la intentio objetiva es la relación de razón que se atribuye a la cosa conocida; mientras que la intentio formal indica el concepto mismo por el cual es formada. Cfr. Cayetano, De nominum analogia..., p. 199, nota $\mathrm{n}^{\circ} 9$.

18 Aquí Soaje sigue a Juan de Santo Tomas, Cursus Philosophicus thomisticus. Reiser, P. (ed.), Marietti, Turin, 1930, t. II, p., q. 2, a, 2, p. 290 b 45-291 a 48. Recordemos que el mismo Juan de Santo Tomás había afirmado que él no tenía nada que agregar a la doctrina de la analogía propuesta por Cayetano.

19 «Analoga secundum inæqualitatem vocantur, quorum nomen est commune, et ratio [o concepto objetivo] secundum illud nomen est omnino eadem, inaequaliter tamen participata». CaYetano, De nominum analogia..., §4, p. 18. El resaltado y los corchete nos pertenecen (lo mismo en el resto de las citas).

20 «Conceptus autem objectalis est res per conceptum formalem repraesentata in illo terminans actum intelligendi, verbi gratia: conceptus formalis leonis est imago illa quam intellectus possibilis format de quiditate leonina, cum vult ipsam intelligere; conceptus vero objectalis ejusdem est 
2. como definición ${ }^{21} \mathrm{u}$ oración que expone la naturaleza de una cosa o la significación de un término. También la entiende como la estructura inteligible, en cuanto conocida, que el nombre significa ${ }^{22}$;

3. como noción a secas ${ }^{23}$, también concepto formal ${ }^{24}$ o signo formal del objeto;

4. como aquello incomplejo obtenido en la simple aprehensión, v.gr., el unívoco animalidad en el hombre y en el buey, porque, si bien en el concretum sendas naturalezas sensitivas son diversas, se identifican abstractivamente en una noción objetiva genérica ${ }^{25}$;

5. como la noción lógica que se forma en el espíritu independientemente de la materia ${ }^{26}, v . g r .$, como el análogo ente se predica de la cantidad y de la substancia proporcionalmente, ello explica que ente sea mayor o superior respecto a sus analogados o que tenga la función lógica de ser más común ${ }^{27}$.

6. como la ratio de la cosa (ratio in re), la cual puede ser entendida: a) como la noción objetiva en cuanto realizada en el sujeto transobjetivo, ya sea en $\operatorname{Dios}^{28}$ o en el resto de los entes ${ }^{29}$; o también como b) la esencia o quididad propiamente hablando ${ }^{30}$, la quidditas qui est in rebus. Es decir que mientras

natura ipsa leonina repraesentata et intellecta [...]».CAYETANo, Comentaria in De ente et essentia D. Thomae Aquinatis, Laurent, Hyancinthi (ed.), Marietti, Roma, 1934, p. 25. Si bien el análisis de Soaje se ciñe al De nominum analogia, hemos traído el pasaje anterior (y también citaremos otro más adelante) del comentario cayetaniano al De ente et essentia del Aquinate por la claridad que tiene al definir la noción de concepto objetivo.

21 «Et est semper sermo de identitate secundum rationem, seu definitionem». CAYETANo, De nominum analogia..., §69, pp. 104-105.

22 Cfr. Cayetano, De nominum analogia ..., pp. 220-221, nota $\mathrm{n}^{\circ} 119$.

23 «Et loquimur de inæqualitate perfectionis: ut corpus nomen commune est corporibus inferioribus et superioribus, et ratio omnium corporum (in quantum corpora sunt) eadem est». CAYETANo, De nominum analogia..., §4, p. 18.

24 "Conceptus formalis est idolum quoddam quod intellectus possibilis format in seipso repraesentativum objectaliter rei intellectae: quod a philosophis vocatur intentio seu conceptus, a theologis vero verbum». CaYetano, Comentaria in De ente..., p. 25.

25 "In univocis vero res illae, puta animalitatis in bove et animalitatis in leone, licet et numero et specie diversae sint, ratione tamen omnino eaedem sunt; ratio enim unius est omnino eadem quod ratio alterius, et, e converso; et propter hoc id quidem quod praedicat animal de homine, idem praedicat omnino de bove, et univocum dicitur et superius homine, leone boveque». CAYETANO, De nominum analogia..., §64, p. 101. Esta ratio obtenida en la simple aprehensión mediante la abstracción se da sólo en los unívocos, según el texto cayetaniano.

26 "Ita quod analogum et univocum conveniunt in hoc, quod utrumque communioris et superioris rationem habet». CAYETANo, De nominum analogia..., §66, p. 103.

27 Si bien el ejemplo es de un análogo —en este caso ente—, según Tomás de Vio, el sentido de ratio al que aquí refiere puede darse tanto en los análogos como en los unívocos.

28 «Nec impedit analogia haec processum formalem ad concludendum de Deo et creaturis praedicatum aliquod eis commune: quoniam accepta sapientiae ratione, et segregatis ab ea per intellectum eis, quae sunt imperfectionis, ex hoc quod id, quod est sibi proprium formaliter sumptum, perfectionem absque imperfectione claudit, concluditur ergo sapientiae ratio non omnino alia, nec omnino haec, sed haec [ratio] proportionaliter est in Deo: quia similitudo inter Deum et creaturam non est univoca, sed analoga». CAYETANo, De nominum analogia ..., §101, p. 161.

29 «Entis enim analogata sunt substantia et quantitas, et non rationes entis in substantia et quantitate. Rationes enim ut dictum est, analogae sunt». CAYETANo, De nominum analogia..., §96, pp. 141 y 143. El resaltado y los corchetes nos pertenecen.

30 «Tam in univocis, quam in æquivocis, quam in analogis quatuor inveniuntur, scilicet duæ res ad minus, æquivocatæ, univocatæ, aut analogatae; et duae res, seu rerum rationes, aequivocationem, univocationem aut analogiam fundantes». CAYETANo, De nominum analogia..., §62, p. 99. "Tum quia proportionalia nomina univoca essent (ut patet ex univocorum definitione), et consequenter 
el término noción objetiva (sentido $a$ ) indica un matiz reflexivo de índole lógico, los vocablos esencia o quididad (sentido $b$ ) hacen referencia a la naturaleza presente en la cosa ${ }^{31} \mathrm{o}$ a ipsa ratio rerum existentium extra animam.

\section{LA RATIO DESPUÉS DE ToMÁs}

Ahora bien, es el mismo Soaje quien reconoce que la noción de ratio sufrió una serie de modificaciones entre los discípulos de Tomás de Aquino ${ }^{32}$; nuestro autor habla más precisamente de una "refundición decisiva» ${ }^{33}$, la cual conduce a que el De nominum analogia no pueda entenderse sin hacer previa referencia a tales modificaciones que dieron lugar a lo que Soaje llama el conceptualismo realista. Dicho de otro modo, para entender el verdadero alcance del opúsculo en cuestión no alcanza con la littera tomasiana, sino que indefectiblemente habrá que echar mano de la glosa de los comentadores. Efectivamente, esto se torna evidente cuando por ejemplo el Cardenal habla del concepto objetivo y del concepto formal, nociones que nunca aparecen en los textos del Aquinate y que serían muy difíciles de interpretar sólo con los escritos tomasianos.

En este orden de ideas, lo que nos interesa resaltar es que en el proceso de refundición al que refiere Soaje surgen por lo menos dos aporías ajenas a la mente aquiniana, las cuales ameritarían ser desarrolladas extensamente en otro escrito, pero que aquí nos parece importante al menos dejar mencionadas. En primer lugar, la noción de ratio sufre una importante inflexión gnoseológica, pues ahora designa en primera instancia un concepto objetivo, el cual finalmente terminará reemplazando o si se quiere opacando la $\operatorname{cosa}^{34}$. Sirvan de muestra de esta problemática dos breves textos del De nominum analogia. En ellos el Cardenal llama a la cosa, sin ambages, concepto objetivo: "Y como en los nombres se hallan tres constitutivos, a saber, el vocablo, el concepto en el alma [concepto formal] y la "cosa extramental o concepto objetivo" [...]». Y unos parágrafos más adelante afirma: «En cambio el análogo en cuanto a la "cosa o concepto objetivo», se distingue como lo que es uno según cierta proporción se distingue de una pluralidad $[\ldots]_{»^{35}}$.

periret proportionalitatis ratio, quae extrema unum simpliciter esse non compatitur; et sic essent proportionalia et non proportionalia: quod intellectus capere nullo modo potest». CAYETANO, De nominum analogia..., §54, p. 87.

31 Cayetano, De nominum analogia..., p. 219-220, nota 111.

32 Cfr. GILson, Étienne, Linguistique et philosophie, Vrin, París, 1969, p. 143. Echauri, Raúl, «Para la historia del concepto», Philosophica 11 (1988), pp. 116-117. Alvira, Tomás, "Esencialismo y Verdad», Anuario filosófico 15 n 2 (1982), pp. 155-156. McCanles, Michael, «Univocalism in Cajetan's Doctrine of Analogy», The New Scholasticism 42 (1968), pp. 18-47. Llano, Alejandro, Metafísica y Lenguaje, Eunsa, Pamplona, 2011, p. 83. Los textos anteriores analizan el tema en la medida en que ratio se considera sinónimo de concepto objetivo, acepción principal en el De nominum analogia según Soaje.

33 Cayetano, De nominum analogia..., p. 253.

34 Cfr. Forlivesi, Marco, «La distinction entre concept formel et concept objectif: Suárez, Pasqualigo, Mastri», trad. di O. Boulnois, Les Études philosophiques, no 1 (2002), pp. 3-30. Más reciente MuÑoz, Ceferino, "Concepto formal y concepto objetivo en Cayetano. Un análisis a partir de su comentario al De ente et essentia», Estudios Filosóficos 179, nº 62 (2013), pp. 49-61.

35 «Et quia in nominibus tria inveniuntur, scilicet vox, conceptus in anima, et "res extra, seu conceptus obiectivus"». "Analogum vero, "quoad rem, seu conceptum obiectivum», distinguitur sicut unum proportione a multis simpliciter; vel (et idem est) sicut multa ut similia secundum 
Con todo, es verdad que Soaje también menciona como presente en Tomás de Vio la acepción de ratio in re para indicar la esencia en sí de la cosa; pero inmediatamente dice que siguiendo al mismo Cayetano prefiere llamarla noción objetiva $^{36}$, incluso afirma que opta por esta denominación en lugar de la de perfección, dado que aquella «muestra explícitamente la conexión de la "ratio in" con la "ratio" en su existir intencional y en su existir objetivo»" ${ }^{37}$ Y aquí surge la segunda de las problemáticas, a saber: el ámbito objetivo o de la objetividad - en este caso representado por el concepto objetivo- tiene un peso tan importante que adquiere un status propio, tal como el mismo Soaje lo señalara en el punto dos referido a los postulados del conceptualismo realista, cuando dice que la cosa además de tener entidad en la realidad extramental y en la mente, existe también objetivamente. Aun así, en la doctrina del Aquinate, tal existencia objetiva es puesta

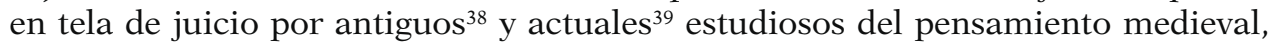
pues la misma no sólo sería un agregado ajeno a la doctrina del Aquinate, sino que llevaría a importantes desviaciones de la misma.

\section{Consideraciones Finales}

Quisiéramos terminar con dos reflexiones que sintetizan la valoración crítica que hemos intentado hacer en este escrito en torno al aporte de Guido Soaje Ramos al esclarecimiento de la noción de ratio.

proportiones a multis absolute». CAYETANO, De nominum analogia..., pp. 54 y 67. Los resaltados en la traducción y en el texto latino son nuestros. Si bien consideramos la versión de Soaje Ramos, hacemos una traducción propia.

36 En un reciente artículo que explica la noción de ratio en Tomás, se afirma: «Ratio, pues, antes que intelecto que razona, es un modo de ser, real, al cual no le afecta nuestra intelección de él [...]. Que para Santo Tomás la ratio diga orden al entendimiento, no ha de llevar a pensar que para él el entendimiento deba necesariamente comparecer en acto en dicha relación». ARgüello, Santiago, "Contribuciones de Alberto Magno y Tomás de Aquino a la noción de ratio rei», Scripta Mediaevalia $\mathrm{n}^{\circ} 5$ vol. 2 (2013), p. 44. Los resaltados pertenecen al autor.

37 Cayetano, De nominum analogia..., p. 258. Los resaltados pertenecen al autor.

38 Es el caso de Domingo Bañez, quien en ocasión de una confutación a Cayetano por el tema del intelecto agente critica la idea de un estado objetivo en el que se encontraría el fantasma, es decir en un estadio intermedio entre lo material y lo inteligible. Cfr. BAÑEz, Domingo, Scholastica Commentaria in Primam Partem Angelici doctoris D. Thomae ad sexagesimam quartam quaestionem complectentia, Typis Haerederum Mathiae Gastii, Salmanticae, 1584, 775 e-776a. Esta idea, y de quien hemos extraído la referencia, está muy bien explicada en García Cuadrado, José, La luz del intelecto agente. Estudio desde la metafísica de Bañez, Eunsa, Pamplona, 1998, p. 228. Una posición distinta es la de SELLÉs, Juan Fernando, «El intelecto agente según Capreolo y Cayetano», Scripta Mediaevalia 7 n 2 (2014), pp. 167-176.

39 Cfr. De Muralt, A., La apuesta de la filosofía medieval. Estudios tomistas, escotistas y gregorianos, Estudio introductorio y traducción Muinelo Cobo, J. C. y Gómez García, J. A. Marcial Pons, Madrid, 2008, pp. 129ss. GILson, É., La filosofía en la Edad Media: Desde los orígenes patrísticos hasta el fin del Siglo XIV, Gredos, Madrid, 2007, pp. 522-523. PeÑa CABrera, A., «Los universales y el problema del concepto en el medioevo», Dianoia vol. 22, n 22, 1976, p. 11. Otra mirada sobre el tema en Vicente BurgoA, L., "Oggetto e obiettività. Le classificazioni degli oggetti del conoscere e il problema dell'oiecttività nel realismo classico», Divus Thomas 102 (1999), pp. 199-245. "Sobre objetos y objetividad. Aspectos del problema de la objetividad del conocimiento en el realismo clásico», Sapientia 52 (1997), pp. 325-345. 
En primer lugar, importa destacar que la significación que tienen los asuntos tratados arriba creemos que se corresponden muy adecuadamente con la doctrina cayetaniana. Empero, también estimamos que tal enseñanza no coincide plenamente con el auténtico pensamiento tomasiano, aunque para Soaje -y en esto nos apartamos de él — ambas enseñanzas se dan sin solución de continuidad. Ahora bien, la posición de nuestro autor es totalmente comprensible toda vez que por casi cinco centurias se sostuvo prácticamente al unísono entre los tomistas la total identidad entre el Aquinate y Cayetano, considerando a este último como alter Thomas $^{40}$. En este sentido, es dable recordar que el estudio de Soaje, que nos hemos ocupado de considerar, se publica en 1949, tres años antes de la aparición de una serie de artículos que Étienne Gilson dedicó al estudio de las esenciales disidencias entre Cayetano y su maestro ${ }^{41}$. Previo a estas investigaciones, nadie o casi nadie había osado señalar diferencias de peso entre ambos dominicos ${ }^{42}$, pues, de alguna manera, era casi inimaginable que el gran defensor y difusor del pensamiento de Tomás de Aquino se apartara y hasta rebatiera su magisterio.

Por otro lado, y aquí la segunda reflexión, llama poderosamente la atención que en la vastísima y diversa bibliografía referida a Cayetano prácticamente no se haga referencia ni a la traducción, ni a las notas, ni al apéndice dedicado a la noción de ratio que presenta el Dr. Soaje. Por nuestra parte, creemos que es un aporte sumamente valioso el de este autor argentino — que nada tiene que envidiarle a los de Maritain y Ramírez, por nombrar a solo dos grandes tomistas contemporáneos-, principalmente porque ha sabido penetrar la forma mentis de Cayetano al tiempo que ha detectado con notable lucidez cuáles son los conceptos metafísicos cayetanianos que están presentes en los tomistas de mayor referencia del siglo $\mathrm{XX}^{43}$.

Consejo Nacional de Investigaciones Científicas y Técnicas (CONICET)

Ceferino P.D. MuÑoz

Centro de Estudios Filosóficos Medievales

Facultad de Filosofía y Letras de la Universidad Nacional de Cuyo y

Universidad de Mendoza.

ceferino.munoz@um.edu.ar

[Artículo aprobado para publicación en diciembre de 2015]

40 Cfr. LÁzaro, N., "Tomás de Vio, el Cardenal Cayetano: un gran desconocido», en: DíEz, R. (ed.), "Vita flumen» 10 años en el pensamiento medieval, Actas de las $\mathrm{X}^{\mathrm{a}}$ Jornadas Nacionales de Filosofia Medieval, Academia Nacional de Ciencias de Buenos Aires, Buenos Aires, 2015, p. 1. El autor también recuerda otras frases con que solía vincularse a ambos dominicos: «Aquinatis quasi vivens» [...] "si vis Thomam intelligere, lege Cajetanum».

${ }^{41}$ Cfr. Gilson, É., «Note sur un texte de Cajétan», Antonianum 27 (1952), pp. 377-380. "Cajétan et l'existence», Tijdschrift voor Philosophie 15 (1953), pp. 267-286. "Nota sur le revelabile selon Cajétan», Mediaeval Studies 15 (1953), pp. 199-206. «Cajetán et l'humanisme théologique», Archives d'histoire doctrinale et littéraire du Moyen Âge 30 (1955), pp. 113-136. "Autour de Pomponazzi», Archives d'histoire doctrinale et littéraire du Moyen Âge 28 (1961), pp. 163-279. Para contextualizar mejor la crítica gilsoniana, se puede ver el artículo de Bonino, Serge-Thomas, «La historiografía de la escuela tomista: el caso Gilson», Scripta Theologica 26 (1994/3), pp. 955-976.

42 Una excepción es la de Cornelio Fabro, quien incluso antes de Gilson había denunciado que la noción tomasiana de ens no era la misma que la de Cayetano. Cfr. FABro, C., La Nozione Metafisica di partecipazione: secondo S. Tommaso d'Aquino, $2^{\circ}$ ed. revisada y aumentada, Societá Editrice Internazionale, Torino, 1950, p. 188. Luego desarrollará esta idea más profundamente en «L’obscurcissement de l’esse dans l’école thomiste», Revue Thomiste 58 (1958), pp. 443-472.

43 Para corroborar esto basta consultar el extenso y erudito aparato de notas que ofrece Soaje en el estudio de marras. Cfr. Cayetano, De nominum analogia..., pp. 197-238. 